\title{
EL DELITO DE CAZA FURTIVA EN TIEMPO DE VEDA. COMENTARIO A LA STS 3566/2020, DE 3 DE NOVIEMBRE
}

\author{
Alfredo Liñán Lafuente \\ Universidad Complutense de Madrid
}

Title: The crime of poaching in closed season. Commentary to STS 3566/2020 of 3 November Sumario: 1. Hechos enjuiciados y calificación jurídica; 2 . El artículo $335 \mathrm{CP}$ originario y su
declaración de inconstitucionalidad; 3 . La actual tipificación del artículo $335.1 \mathrm{CP} ; 4$. El
artículo 335.2 CP y su compatibilidad con el art. 335.1 CP; 5 . Conclusiones.

Resumen: La Sala Segunda del Tribunal Supremo en su sentencia ${ }^{\circ}$ $3566 / 2020$, de 3 de noviembre, ha concluido que la caza de una especie no protegida en temporada de veda es siempre constitutiva de un delito del art. 335.1 CP. En el presente artículo se analiza la sentencia, el artículo 335 1. y 2 CP y se plantean las consecuencias que se pueden derivar de la interpretación por la que opta el Tribunal Supremo. fauna.

Palabras clave: Caza; veda; biodiversidad; especie amenazada;

Abstract: The Second Chamber of the Supreme Court in its judgment No. 3566/2020, of 3 November, has concluded that the hunting of an unprotected species during the season closed to hunting is always an offence under art. 335.1 CP. This article assesses the judgment and article 335.1. and 2 of the Penal Code and it raises the consequences that can stem from the interpretation chosen by the Supreme Court.

Keywords: Hunting; closed season; biodiversity; endangered species; wildlife. 


\section{Hechos enjuiciados y calificación jurídica}

Cualquiera que conozca, aun de lejos, el mundo de la caza podrá fácilmente imaginarse los hechos que han dado lugar a la resolución que se va a comentar, pues aborda la práctica común, en muchas zonas rurales, del cazador furtivo que valiéndose de la noche sale al aguardo de piezas de caza mayor en temporada de veda - habitualmente sucede en las noches de verano - para hacerse con su carne y sus trofeos.

Los hechos que se enjuician sucedieron una noche de junio de 2016, en las estribaciones de la sierra de los Pedroches, el término municipal de El Viso (Córdoba), una zona bastante cercana a los límites de la Comunidad Autónoma de Castilla La Mancha (por la provincia de Ciudad Real) y de la Comunidad Extremeña (por la provincia de Badajoz). Durante la noche del 16 de junio se escucharon en la finca «El Salado» 5 disparos. Teodosio fue el autor de los disparos que consiguieron abatir a un muflón y a cuatro ciervos. Sobre la 1:30 de la madrugada, Teodosio fue interceptado con la cabeza del muflón y un cuchillo de $10 \mathrm{~cm}$ de hoja. Cerca de este lugar se encontró un barreño con 45 kilos de carne de las piezas abatidas. Al día siguiente se encontraron los restos de los animales muertos.

La caza de estas especies estaba prohibida en esa fecha, por orden de 1 de julio de 2016 de la Comunidad Autónoma de Andalucía, por la que se fijaban las vedas y los periodos hábiles de caza. Teodosio no tenía permiso del titular del coto para cazar en la finca «El Salado».

Teodosio fue condenado por Sentencia del Juzgado de lo Penal $n^{\circ} .1$ de Córdoba el 12 de abril de 2019 por un delito consumado contra la fauna del artículo $335.1 \mathrm{CP}$ y por otro delito consumado contra la fauna del artículo 335.2 CP. Dicha resolución fue confirmada por la Sección III de la Audiencia Provincial de Córdoba en su sentencia de 11 de octubre de 2019. Contra ésta se interpuso el recurso de casación que ha dado lugar a la STS 3566/2020 de 3 noviembre.

El artículo $335.1 \mathrm{CP}$ castiga con una pena de multa de 8 a 12 meses e inhabilitación especial para el ejercicio del derecho a cazar o pescar por tiempo de 2 a 5 años, al que cace o pesque especies no amenazadas ${ }^{1}$ cuando esté expresamente prohibido por las normas específicas sobre su caza o su pesca.

Por su parte, el artículo $335.2 \mathrm{CP}$ castiga con una pena de multa de 4 a 8 meses e inhabilitación especial para el ejercicio del derecho a cazar, pescar o realizar actividades de marisqueo por tiempo de 1 a 3 años, al

1 Ya que el castigo por cazar o pescar especies protegidas se tipifica en el artículo 334 $\mathrm{CP}$ con una pena mayor. 
que cace, pesque o realice actividades de marisqueo relevantes sobre especies no amenazadas en terreno público o privado ajeno, sometido a régimen cinegético especial, sin el debido permiso de su titular o sometido a concesión o autorización marisquera o acuícola sin el debido título habilitante. Este artículo in fine especifica que estas penas se impondrán, además de las penas que pudieran corresponderle, en su caso, por la comisión del delito previsto en el apartado 1 de este artículo.

\section{El artículo 335 CP originario y su declaración de inconstitucionalidad}

El artículo 335 CP fue incorporado al Código Penal de $1995^{2}$ con una redacción sutilmente distinta a la actual y que tras distintas resoluciones judiciales fue declarado inconstitucional por la STC 101/2012, que resolvió una cuestión de inconstitucionalidad planteada 11 años antes por el Juzgado de lo Penal $n^{\circ} 6$ de Granada. La Sentencia es una declaración más simbólica que efectiva, pues el artículo 335 CP ya había sido modificado varios años antes ${ }^{3}$ precisamente para salir al paso de las advertencias de inconstitucionalidad que ya se habían puesto de manifiesto por varias resoluciones judiciales ${ }^{4}$.

El artículo $335 \mathrm{CP}$, en su redacción originaria, se encontraba tipificado del modo siguiente: «El que cace o pesque especies distintas a las indicadas en el artículo anterior, no estando expresamente autorizada su caza o pesca por las normas específicas en la materia, será castigado con la pena de multa de cuatro a ocho meses».

El objeto material de protección del delito no ha variado y antes de analizar las razones que llevaron a declarar su inconstitucionalidad procede concretarlo para que sirva como referencia a lo largo del artículo. Las especies protegidas en este artículo son las que no se encuentran especificadas en el artículo $334 \mathrm{CP}$, que circunscribe su ámbito típico a las especies amenazadas. Para determinar cuáles son se habrá de acudir - al estar ante un claro ejemplo de ley penal en blanco - a la normativa estatal y autonómica. De manera habitual la jurisprudencia ha optado por aplicar un criterio formal de «especie amenazada» y remitirse al catálogo de especies amenazadas - nacional y en ocasiones autonómico - para determinar si la especie cazada concuerda con el objeto de protección del artículo $334 \mathrm{CP}^{5}$ por encontrarse catalogada en alguna de las cuatro categorías establecidas en la Ley 4/1989, de 27

Ley Orgánica 10/1995, de 23 de noviembre.

Por la Ley Orgánica 15/2003, de 25 de noviembre

Vid. STS 1302/1999, de 28 de febrero.

5 Aunque el Tribunal Supremo en sus primeras sentencia optó por el criterio material de la especie amenazada, que exige la constatación de una situación de hecho 
de marzo, sobre espacios naturales y de la flora y la fauna silvestre (en peligro de extinción, vulnerables, sensibles a la alteración de su hábitat y de interés especial), a pesar que el Tribunal Supremo advirtió desde las primeras sentencias que se enfrentaron a la interpretación de este tipo penal que junto a la denominación formal de especie amenazada, se debía constatar una situación de amenaza real y efectiva sobre la especie $^{6}$. Así, la STS 829/1999 de 19 de mayo advierte que ${ }^{7}$ : [...] la mera inclusión formal en un determinado catálogo no es suficiente para declarar conformado el ilícito penal si no concurre la debida constatación de que el animal de que se trate forma parte de una especie efectiva y objetivamente amenazada. De lo contrario, como con algunas gotas de sorna destaca la doctrina, nos encontraríamos con que cazar algún ejemplar de las cinco especies de sapos, diez especies de lagartijas, nueve de culebras, veintiuno de murciélagos o cinco de ranas, serían constitutivos de un delito sancionable con hasta dos años de prisión.

La cantidad de especies catalogadas como protegidas o vulnerables hace complicado, en muchas ocasiones, que un ciudadano medio pueda saber si la especie que ha matado se encuentra amenazada o no. Obviamente ello no sucede con las especies más conocidas en peligro de extinción - lince, oso pardo, lobo, ... - pero muchas otras incluidas en el catálogo pueden ser fácilmente confundidas, por ejemplo, una rana ágil (Rana dalmatina) o un cangrejo de río (como Austropotamobius pallipesque) que constan como especies vulnerable en el catálogo nacional. Éste se ha de combinar con los catálogos de las especies amenazadas a nivel autonómico ${ }^{8}$, lo que complica aún más la diligencia de un hombre medio para la identificación de especies - flora y fauna - que están protegidas.

de amenaza real y efectiva sobre la especie, más que por el carácter formal de su inclusión en el catálogo de protección.

6 Acogiendo así la interpretación expuesta por la doctrina. Vid. HaVa García, E., «Delitos relativos a la protección de la flora y la fauna», en TerRadillos BASOco, J., Derecho penal del medio ambiente. Trotta, Madrid, 1997. Esta autora ya advertía la necesidad «que el juez valore, en el caso concreto, si la conducta enjuiciada ha puesto en peligro el mantenimiento de la diversidad biológica. Solo de este modo es posible respetar el principio de intervención mínima y, en concreto, el carácter fragmentario del Derecho Penal, además de salvar la inconstitucionalidad del precepto, que resultaría de una interpretación meramente literal de éste».

7 En sentido similar STS 2227/2001, de 29 de noviembre: «Ello quiere decir que la mera inclusión en el catálogo en la categoría de «interés especial» no es suficiente para estimar que se trata de una especie amenazada, de la misma forma que su inclusión no supone la exclusión de dicha condición cuando ésta materialmente resulta acreditada en los autos, es decir, se trata de establecer la preferencia de la antijuricidad material sobre la formal por la mera inclusión en los catálogos del artículo 29 de la Ley 4/1989».

8 Sirva como ejemplo el catálogo de la Comunidad Autonómica de Extremadura http://extremambiente.juntaex.es/index.php?option=com_content\&view=article\&id=1353 \&Itemid $=165$. 
Por lo tanto, el objeto material del artículo $335 \mathrm{CP}$ son aquellas especies que no se encuentran amenazadas y que por lo tanto son cazables de acuerdo a la regulación de la administración autonómica que corresponda, ya que la Constitución Española en su artículo 148.1.11ª permite la asunción de las competencias en pesca en aguas interiores, marisqueo y acuicultura, caza y pesca fluvial a las Comunidades Autónomas, y todas ellas lo han regulado en su Estatuto y normativa autonómica sectorial.

El problema del antiguo artículo $335 \mathrm{CP}$ estribaba en que el modo de tipificar el contenido del injusto era excesivamente vago, pues dependía de que la caza o pesca del animal no amenazado hubiera sido autorizado expresamente, por lo que la ausencia de regulación expresa incluía en el ámbito de la tipicidad penal cualquier acto de caza o pesca no expresamente regulado. Ello atentaba contra el principio de legalidad y contra el de seguridad jurídica, pues, incluso acudiendo a normas extrapenales, no era posible identificar con la necesaria y suficiente precisión la norma de reenvío. El pleno de Tribunal Constitucional declaró inconstitucional esta redacción del artículo $335 \mathrm{CP}$ en su sentencia de $\mathrm{n}^{\circ}$ 101/2012 de 5 de junio de 2012 (a pesar de que el artículo ya había sido reformado en 2003) al concluir que la norma penal cuestionada «no contiene efectivamente el núcleo esencial de la prohibición toda vez que remite íntegramente y sin ninguna precisión añadida la determinación de las especies no expresamente autorizadas a las normas específicas en materia de caza, de modo que es el Gobierno, a través de normas reglamentarias y, en particular, los correspondientes listados de especies cinegética, y no el Parlamento, el que en forma por completo independiente y no subordinada a la ley termina en rigor por definir libremente la conducta típica. De hecho, con el citado art. $335 \mathrm{CP}$ en la mano, basta simplemente con que la administración guarde silencio y no se pronuncie sobre la caza o no de una determinada especie animal para que su captura o muerte pase a integrar el tipo penal que consideramos. Todo lo cual supone, según hemos advertido en otras ocasiones, una vulneración de la garantía formal del principio de legalidad penal.»

Y es que con la antigua regulación, la persecución y captura de cualquier especie que no estuviera regulada por carecer de interés cinegético - ratones, gatos, perros salvajes, topos, etc. - era una conducta típica al no estar expresamente autorizada, aunque la ausencia de regulación no atendiese a la salvaguarda de la especie sino al poco interés que despierta ese tipo de animales para los cazadores.

La citada sentencia del Tribunal Constitucional acoge la argumentación que con anterioridad ya había propuesto el Tribunal Supremo en su sentencia $\mathrm{n}^{\circ} .130 / 1999$ de 8 de febrero, al casar una sentencia condenatoria derivada de la caza de un jilguero, para la cual se necesitaba licencia. El Tribunal Supremo absolvió al acusado al considerar que la falta de autorización individual para cobrar la pieza de una especie autorizada a cazarse genéricamente no integraba el tipo penal y constituía únicamen- 
te una infracción administrativa, iniciándose una línea jurisprudencial que negaba la tipicidad del artículo $335 \mathrm{CP}$ de las acciones de caza o pesca en época de veda ${ }^{9}$. Junto con ello, en la sentencia se analizan todas las carencias de las que adolecía la antigua regulación del artículo 335 $\mathrm{CP}$, advirtiendo que en este supuesto el tipo penal no contenía el núcleo esencial de prohibición, desplazándose integramente la calificación como delictiva de la conducta a la normativa administrativa, que en este supuesto no cumple con la función accesoria de delimitar o complementar el tipo delictivo sino que lo fundamenta y define en su totalidad.

Todo ello llevó al legislador a modificar la redacción del artículo 335 CP en la Ley Orgánica 15/2003 en un aspecto concreto, pero esencial, pues pasó de castigar la caza y la pesca «que no esté expresamente autorizada" a aquella que "esté expresamente prohibida», mutando el prisma de prohibición de lo no permitido expresamente a lo prohibido concretamente.

\section{La actual tipificación del artículo 335.1 CP}

La jurisprudencia relativa a la antigua redacción del artículo 335 CP había negado la tipicidad de las acciones de caza en época de veda bajo la interpretación de que la caza o pesca de la especie estaba autorizada de manera genérica, aunque expresamente a determinadas épocas del año. Así, la STS 1726/2002, de 22 de octubre, concluyó que: Por tanto, aquí lo contemplado no es una actividad de caza de animales cuya captura no esté expresamente autorizada, sino la referida a los pertenecientes a una especie para cuya captura se precisa de licencia administrativa o permiso, del que carecían los acusados. Así, pues, se ha de concluir, como lo hacía la resolución tantas veces citada, en el sentido de que la caza afectó a una especie autorizada, si bien sometida a un régimen especial de permisos y limitaciones, de ahí que sea correcta la estimación del Tribunal sentenciador en el sentido de que no concurrió el elemento esencial definidor del tipo.

Por la tanto, la jurisprudencia concluía - debido a la deficiente redacción del precepto - que si sobre la especie afectada existía una autorización de caza la conducta no era delictivo, aunque se hubiere llevado a cabo sin licencia o fuera de las épocas de año permitidas, pues su caza - aun de manera genérica - estaba expresamente autorizada por la administración.

Con este precedente no ha de extrañar que uno de los motivos del recurso de casación, que dio origen a la sentencia comentada, argumentase que los hechos no eran típicos pues existía una autorización para la caza de las especies abatidas - ciervo y muflón — , aunque en el momento en

9 Vid. STS 22 de octubre de 2002; STS de 23 de febrero de 2006. 
que se cometieron los hechos era en periodo vedado para la caza. En este sentido, alega el recurrente que: [...] estamos hablando de una caza que afecta a una especie autorizada, sin bien sometida a un régimen especial de permisos y limitación [...] En otras palabras: quien caza una especie en veda es porque existe un periodo en el que sí puede ser cazada (es cinegética), por lo tanto no está cometiendo ningún delito contra la fauna, sino que lo está cometiendo es una infracción administrativa, que no puede considerarse grave $^{10}$. El Tribunal concluye que no tiene razón el recurrente ya que el nuevo enunciado del artículo $335 \mathrm{CP}$ no delimita el espectro típico desde la perspectiva de lo que no esté «expresamente autorizado» sino desde lo que esté «expresamente prohibido».

La caza del muflón y del ciervo, en la sierra de Córdoba donde se produjeron los hechos, sólo estaba permitida del 15 de octubre de 2016 al 12 de febrero del 2017, por la Orden de 1 de julio de 2016 de la Consejería de Medio Ambiente y Ordenación del Territorio de la Comunidad de Andalucía, por lo que el Tribunal concluye que la actividad cinegética sólo estaba permitida en ese periodo temporal. Y si bien ello es cierto, cabe plantearse si se puede entender que esté «expresamente prohibida» el resto del año pues como advertía PRATS CANUT ${ }^{11}$, las normas que regulan la caza y pesca, y muy significativamente las normas autonómicas de veda, suelen más bien establecer condiciones modales, temporales y espaciales de autorización para la caza o pesca, que prohibiciones expresas, lo cual se hace de forma excepcional con determinadas especies. La Sala no entra en esta disquisición y considera implícitamente que la caza que se encuentra fuera del periodo permitido, está prohibida.

Es cierto que la modificación de tipo penal varió la manera de entender el núcleo de prohibición, y que la jurisprudencia anterior referida al antiguo artículo 335 CP no sería aplicable a la redacción actual, pero en mi opinión los problemas de constitucionalidad (referidas a la garantía formal del principio de legalidad) del artículo persisten aún con su actual redacción, pues el tipo penal sigue sin precisar el núcleo esencial de la prohibición penal, que coincide con la prohibición en el ámbito administrativo. El legislador de 2003 lo único que hizo fue cambiar el término «expresamente autorizado» a «expresamente prohibido" y si bien este cambió sirvió para dotar de mayor seguridad jurídica al ciudadano que se enfrenta a esta norma, no resolvió el problema de fundamentar el injusto y el ataque al

10 Reproducido en el Fundamento de Derecho 3 de la STS 570/2020.

11 Prats Canut, M., en Quintero Olivares, G/Morales Prats, F., Comentarios a la Parte Especial del Derecho Penal. Thomson, Madrid, 2007 (6 ${ }^{\mathrm{a}}$ ed.), p. 1264. 
bien jurídico protegido (biodiversidad) para distinguirlo de la mera infracción administrativa ${ }^{12}$.

De este modo, el reproche que hizo el Tribunal Constitucional en su Sentencia 101/2012 es plenamente reproducible y aplicable al artículo 335 CP en su actual redacción. Así, el Tribunal Constitucional concluyó que: Esta libertad absoluta e incondicionada para que sea una norma la que defina el tipo es, en efecto, manifiesta puesto que, como prueba de su propio tenor literal, la norma penal cuestionada no contiene tampoco ninguna exigencia específica de lesión o puesta en peligro del bien jurídico protegido (la fauna silvestre) que sirva para precisar el núcleo esencial de la prohibición penal y cualificar de ese modo, entre las acciones abstractas que identificar (cazar o pescar), las que por ese motivo merecen reproche penal. Este déficit en la definición del núcleo esencial de la prohibición es tanto más acusado y significativo si comparamos ahora el artículo 335 CP cuestionado con el resto de las normas penales previstas en el propio capítulo V del Título XVI del libro II del Código Penal de 1995, sobre "los delitos relativos a la protección de la flora y la fauna», y en los que el legislador penal sí exige que la correspondiente conducta, además de vulnerar las normas extrapenales en la materia, afecte a especies de flora y fauna "amenazadas» (arts. 332 y 334 C.P), «periudique el equilibrio biológico» (art.333 CP) o consista en la utilización de instrumentos de artes de caza o pesca de innegable "eficacia destructiva» (art.336 CP). Lo que supone ciertamente un plus de antijuridicidad material que coadyuva a precisar la correspondiente conducta penal típica y permite cumplir con la comentada exigencia constitucional (STC 34/2005, de 17 de febrero); una circunstancia, sin embargo que, como se ha comprobado, no concurre en el caso del artículo 335 CP.

Si se analiza el artículo 335 CP se puede concluir que su tipificación adolece de los mismos defectos - en este aspecto concreto - que la antigua redacción, pues no incorpora ningún elemento de peligro o resultado que se incluya en la conducta típica junto con la mera infracción de la norma extrapenal que pueda fundamentar el plus de antijuridicidad necesario para la intervención del Derecho penal. Si se analiza la diversidad de la regulación administrativa que a nivel nacional, y sobre todo autonómico, se han desarrollado sobre la caza y la pesca se colegirá que este plus de antijuridicidad es necesario para no dejar en manos del legislador autonómico decidir qué es y qué no es delito. Tal y como advertía Prats CANUT ${ }^{13}$, en relación con la problemática de considerar al antiguo artículo $335 \mathrm{CP}$ como accesorio al acto administrativo, en donde el delito podía quedar sin efecto

12 En este sentido, Vid. Matellanes Rodríguez, N., Derecho penal del Medio Ambiente. Iustel, Madrid, 2008, p. 193.

13 Prats Canut, M., en Quintero Olivares, G/Morales Prats, F., Comentarios..., op. cit., p. 1263. 
por la previa autorización administrativa del órgano competente, con la regulación tras la Ley Orgánica 15/2003 las dudas acerca de la constitucionalidad de este artículo se mantienen, puesto que actos administrativos lo hay tanto de autorización como de prohibición, si bien es cierto que la expresión utilizada ahora "cuando esté expresamente prohibido por las normas específicas sobre la caza o pesca» induce a menos errores que el término «expresamente autorizadas».

La sentencia comentada no es ajena a este problema y se pronuncia expresamente sobre este déficit de injusto, advirtiendo que pese a la literalidad del artículo $335 \mathrm{CP}$, la Sala entiende que no todo incumplimiento de una prohibición administrativa de caza puede ser calificada como delito. Este precepto no puede ser degradado a la condición de un delito puramente formal de desobediencia de la normativa administrativa. Lo prohíbe el principio de intervención mínima, esto es, la necesidad de reservar la respuesta penal para aquellas conductas más desvaloradas. Ante esta afirmación cabe preguntarse cómo resuelve entonces la Sala el supuesto planteado para mantener la condena de instancia sin entrar en contradicción. Para ello el Tribunal aclara que entre todo el elenco de prohibiciones administrativas se deberá analizar si la norma quebrantada encierra un elemento que pueda colmar la antijuridicidad material, concluyendo que la regulación administrativa de la temporada de veda se ha de incluir en este último grupo. A esa conclusión se llega en la sentencia al considerar que los periodo de veda responden a razones de orden biológico para facilitar la reproducción de la especie, afirmando que: La definición de los periodos prohibitivos de carácter cíclico tienen un valor estratégico de primer orden para la protección de la vida animal. Nada de ello, pues, es ajeno a la protección de los recursos naturales renovables. El equilibrio en la conservación de las especies, en definitiva, la biodiversidad y la propia supervivencia de la fauna no pueden considerarse de ínfimo valor axiológico.

La consecuencia que tiene esta interpretación es que, tras esta sentencia, toda acción de caza o pesca que se lleve a cabo en la temporada de veda será constitutiva del delito de artículo $335 \mathrm{CP}$, ya sea abatiendo una paloma, un jabalí o pescando una carpa. Si bien coincido con la interpretación de la finalidad del periodo de veda que se expone en la sentencia, en mi opinión no es suficiente el quebranto de la prohibición de cazar para constituir una acción delictiva, pues por mucho que la temporada de veda sirva para la reproducción de las especies en temporada de cría, no puede presumirse iure et de iure que la caza de una especie en época de veda afecta al bien jurídico protegido de la biodiversidad ${ }^{14}$. Como acertadamente advierte Hava

14 Entendido, según el artículo 2, párrafo quinto del Convenio sobre Diversidad Biológica de las Naciones Unidas (Nairobi, 22 de mayo de 1992) como: «La variabilidad de organismo vivos de cualquier fuente, incluidos, entre otras cosas, los ecosistema terres- 
GARCíA $^{15}$ al examinar el bien jurídico protegido biodiversidad, tras constatar en su caso la producción de un resultado material exigido en el tipo, deberá comprobarse si el concreto comportamiento puso en peligro la diversidad biológica para afirmar la existencia del injusto penal. De este modo se consigue acotar notablemente el alcance de los tipos, reforzando la vigencia de los principio de intervención mínima y seguridad jurídica, al tiempo que se facilita el deslinde entre la infracción penal y la administrativa.

Siguiendo con la línea doctrinal iniciada por la citada autora ${ }^{16}$, en los supuestos como los examinados en la sentencia se habrá de analizar si además de concurrir los presupuestos objetivos y subjetivos del tipo, la acción ha puesto en peligro en bien jurídico protegido ${ }^{17}$, y para ello se habrá de valorar el número de piezas abatidas, la población de la concreta especie en la zona donde se ha cazado, la época del año (no afecta de igual manera al inicio o al final de la temporada de veda, que en meses donde la especie acaba de parir y ha de ocuparse de las crías), para determinar si la acción puso en riesgo el bien jurídico protegido.

Por poner un ejemplo, el cazar un conejo fuera en la temporada de veda puede ser un acto inocuo respecto del bien jurídico - si se constata que en la zona existen suficientes ejemplares para que no afecte - o lesivo si, por ejemplo, la población de conejos se ha visto disminuida de un modo alarmante por una enfermedad (como sucedió con la mixomatosis).

Por otro lado, se ha de tener en cuenta que las temporadas de veda, respecto de las mismas especies y en Comunidades Autónomas colindante no son coincidentes, como debiera ser si se parte de que lo que se protege es el periodo de apareamiento y reproducción de las especies, que debe ser similar en la misma zona. Retomando el supuesto de hecho que resuelve la STS 3566/2020, si se analiza la temporada de veda del ciervo y el muflón en Andalucía, Extremadura y Castilla La Mancha (las tres comunidades fronterizas con el lugar donde se producen los hechos), se puede constatar que en Andalucía (en la

tres y marinos y otros ecosistemas acuáticos y los complejos ecológicos de los que forman parte; comprende la diversidad dentro de cada especie, entre las especies y de los ecosistemas».

15 Hava García, E., «Delitos relativos a la protección de la flora y la fauna: diez años de vigencia», en Quintero Olivares, G; Morales Prats, F. (Coords.), Estudios de derecho ambiental. Libro homenaje al Profesor Josep Miquel Prats Canuts. Tirant lo blanch, Valencia, 2008, p. 1020.

16 Vid. Hava García, E. «Delitos relativos..., op. cit., p. 1029.

17 En este sentido, Vid. Prats Canut, M., en Quintero Olivares, G/Morales Prats, F. Comentarios..., op. cit., p. 1264. Afirma este autor que: «... no basta con la mera acreditación de la conducta de caza o pesca de especies expresamente prohibidas, sino que en aras a respetar el principio de ofensividad debe exigirse un plus de desvalor de resultado centrado en la puesta en peligro del bien jurídico biodiversidad». 
temporada de caza 20/21) se permite la caza del ciervo y el muflón del 17 de octubre de 2020 al 14 de febrero de $2021^{18}$, en Extremadura del 12 de octubre de 2020 al 21 de febrero de $2021{ }^{19}$ y en Castilla La Mancha del 8 de octubre al 21 de febrero de $2021^{20}$.

Ante ello, difícilmente puede afirmarse que se ha puesto en riesgo la biodiversidad si en Córdoba se abatiese un ciervo el 18 de febrero de 2021 - y por tanto ya en temporada prohibida - cuando en la vecina provincia de Badajoz se permite la caza hasta el 21 de febrero, pues las fronteras de las provincias obviamente no afectan al movimiento de los animales salvajes ${ }^{21}$.

Consciente de las distintas modalidades de situaciones que pueden producirse la Sala advierte en su sentencia de la irrenunciable necesidad de que los jueces y tribunales, en el momento de ponderar el juicio de tipicidad, asuman unos criterios hermenéuticos teleológicamente vinculados al respeto y a la conservación de la biodiversidad, impidiendo así que infracciones formales con encaje en la microliteralidad del art. 335 conviertan en delito lo que puede ser adecuadamente tratado en el ámbito de la sanción administrativa. Son muchas las prohibiciones expresas impuestas por las normas específicas sobre caza. Algunas de ellas relacionadas con licencias o habilitaciones personales de los cazadores, otras con los limites geográficos naturales que separan el territorio de cada comunidad autónoma o con el número o peso del ejemplar capturado. Para que una infracción de esta naturaleza sea susceptible de respuesta penal será indispensable exigir un plus de ofensividad, un mayor desvalor material del resultado. Solo las conductas que vulneren o pongan en peligro el bien jurídico biodiversidad son merecedoras de sanción penal.

Así, puede comprobarse que la Sala modula en este último párrafo la conclusión a la que llega en la sentencia, al afirmar que se habrá de analizar si en la conducta infractora de una norma administrativa que prohíbe la caza existe ese plus de antijuridicidad necesario para que intervenga el Derecho penal, y ello debe ser extensible en mi opinión a la caza en época de veda, tal y como se ha expuesto en la líneas anteriores,

18 Resolución de 5 de mayo de 2020, de la Dirección General de Medio Natural, Biodiversidad y Espacios Protegidos, por la que se publican los períodos hábiles de caza para la temporada 2020/2021.

19 Orden de 27 de marzo de 2020 General de Vedas de Caza para la temporada 2020/2021, de la Comunidad Autónoma de Extremadura.

20 Orden 88/2020, de 19 de junio, de la Consejería de Desarrollo Sostenible, por la que se fijan los períodos hábiles de caza y las vedas aplicables con carácter general a todo el territorio de la comunidad autónoma de Castilla-La Mancha para la temporada cinegética 2020-2021.

21 De hecho este problema surge en las fincas de caza que abarcan dos comunidades autónomas, pues en una parte de la finca puede cazarse una especie que en otra se encuentra en veda. 
sin que pueda presumirse que todo abatimiento en época prohibida lesiona o pone en peligro, por sí, el bien jurídico protegido.

\section{El artículo 335.2 CP y su compatibilidad con el art. $335.1 \mathrm{CP}$}

La sentencia de instancia del supuesto objeto de cometario condenó a Teodosio por un delito del artículo 335.1 CP y otro del artículo 335.2 CP, debido a que el lugar donde abatió a los animales era un coto de caza y lo hizo sin contar con la autorización del titular del coto.

El artículo $335.2 \mathrm{CP}$ castiga a: El que cace o pesque o realice actividades de marisqueo relevantes sobre especies distintas de las indicadas en el artículo anterior en terrenos públicos o privados ajenos, sometidos a régimen cinegético especial, sin el debido permiso de su titular o sometidos a concesiones o autorización marisquera o acuícola sin el debido título administrativo habilitante, será castigado con la pena de multa de cuatro a ocho meses e inhabilitación especial para el ejercicio del derecho a cazar, pescar o realizar actividades de marisqueo por tiempo de uno a tres años, además de las penas que pudieran corresponderle, en su caso, por la comisión del delito previsto en el apartado 1 de este artículo.

Este tipo delictivo recupera una conducta prohibida y considerada delictiva en el derogado artículo 42 de la Ley 1/1970 de Caza (con alguna matización sobre el valor cinegético de lo cazado $^{22}$ ), que pasó a tener consideración de infracción administrativa en virtud de la disposición derogatoria única 1 e) de la Ley Orgánica 10/1995, de 23 de noviembre. La Ley Orgánica 15/2003 reintrodujo esta conducta en el ámbito penal en el artículo 335.2 CP y de nuevo, una infracción administrativa pasó a ser considerada delito sin reparar el legislador en el plus de ofensividad que se ha de exigir para que ello suceda.

Si se analiza con detenimiento el artículo, se puede concluir que estamos ante una conducta que, en sí, no atenta contra el bien jurídico protegido del primer apartado del artículo $335 \mathrm{CP}$, pues el hecho de cazar especies no amenazadas cuando no esté expresamente prohibido, no afecta a la biodiversidad en ninguna de sus modalidades ${ }^{23}$. Lo que se protege en este apartado del artículo es el derecho de la administración, o de los titulares de cotos privados de caza, de decidir a quién autorizan para que cace en una zona determinada. Es más, cuando se comprueba

22 Art. 42. Ley 1/1970. f) Los que, sin el debido permiso, cazaren en terrenos sometidos a régimen cinegético especial cuando el valor cinegético de lo cazado exceda de 2.500 pesetas.

23 Vid. Prats Canut, M., en Quintero Olivares, G./Morales Prats, F., Comentarios..., op.cit., pp. 1265-1266. 
que el consentimiento del titular del coto o de la administración elimina la tipicidad de la conducta - sin el debido permiso de su titular o sometidos a concesiones o autorización marisquera o acuícola sin el debido título administrativo habilitante - ha de concluirse que estamos ante otro bien jurídico disponible que poco tiene que ver con la protección del medio ambiente, y más con el derecho del titular de un coto a regular la caza y obtener un beneficio por ello.

Ello lleva a plantear si este tipo de conductas - que no protegen el bien jurídico de los delitos contra la fauna - deberían encontrarse en este apartado y aún más, si debe ser un bien jurídico digno de tutela penal o sería suficiente con la regulación y sanción del Derecho administrativo, tal y como se habría de concluir con la aplicación de los tan nombrados y maltratados principios de ofensividad y de intervención mínima del Derecho penal.

La Sentencia comentada no entra a valorar la condena por el artículo 335.2 CP debido a que la misma no había sido objeto del recurso de casación, pero sí conviene plantear si la cláusula concursal que se incluye en el artículo 335.2 CP hablita para castigar una única conducta por dos delitos sin infringir el principio bis in idem. El artículo 335.2 $\mathrm{CP}$ incluye en su último párrafo la siguiente precisión: además de las penas que pudieran corresponderle, en su caso, por la comisión del delito previsto en el apartado 1 de este artículo. Por ello, aquel furtivo que cace en época de veda en terreno ajeno sin tener la debida autorización por el titular del coto se le castigará por ambos tipos delictivos. Esta solución concursal solo es defendible, a mi entender, si se considera que los numerales 1 y 2 del artículo $335 \mathrm{CP}$ protegen bienes jurídicos distintos - el primero la biodiversidad y el segundo el derecho del titular (privado o administración) del coto de regular la actividad cinegética - por lo que la misma conducta afectaría a dos valores protegidos por los dos apartados del mismo artículo. Si se colige que el bien jurídico protegido por ambos delitos es el mismo - biodiversidad - el castigo por ambos tipos infringiría, en mi opinión, el bis in idem al castigarse dos veces una única conducta que afectaría al mismo bien jurídico protegido.

Ello avala la tesis aquí defendida de que el artículo $335.2 \mathrm{CP}$ no defiende el bien jurídico biodiversidad, por lo que debería ser eliminado de este artículo y la conducta debería regresar al ámbito administrativo sancionador ${ }^{24}$, del que, por lo expuesto, no debió ser transferido al Derecho penal con posterioridad a la promulgación de la de la Ley Orgánica 10/1995.

24 En el mismo sentido, Matellanes Rodríguez, N., Derecho penal..., op. cit., p. 194. 


\section{Conclusión}

La STS 3566/2020, de 3 de noviembre establece que cazar a cualquier animal no amenazado en temporada de veda constituye un delito del artículo $335.1 \mathrm{CP}$, pues al llevar a cabo la acción en un periodo prohibido que se establece para facilitar la reproducción y repoblación de los animales, esta conducta lesiona el bien jurídico protegido (biodiversidad). No obstante, el Tribunal Supremo, consciente de los problemas derivados de la aplicación directa de la regulación administrativa de caza para determinar el comportamiento típico delictivo advierte en la sentencia comentada de la irrenunciable necesidad de que el juez pondere, en cada caso concreto, la infracción administrativa con la lesión del bien jurídico protegido, para evitar que se sancione penalmente lo que no dejan de ser infracciones formales administrativas.

En mi opinión, la regulación del artículo 335.1 CP sigue adoleciendo de ciertas carencias que socavan su legitimidad al no incorporar algún resultado de peligro o de lesión que se incluya en la conducta típica, junto con la mera infracción de la norma extrapenal, que pueda fundamentar el plus de antijuridicidad necesario para la intervención del Derecho penal. La redacción del artículo $335 \mathrm{CP}$ resulta constitucionalmente cuestionable por afectar a la garantía formal del principio de legalidad, por lo que debería ser reformado e incluir en el tipo un resultado de peligro o de lesión del bien jurídico protegido, tal y como se incluye en los demás delitos que protegen el medio ambiente.

Por otro lado, el apartado segundo del artículo $335 \mathrm{CP}$ protege un valor distinto al bien jurídico biodiversidad, pues se focaliza en el derecho que tienen los titulares de los cotos de caza para regular su actividad cinegética. En este supuesto se comprueba, con mayor nitidez que lo que se castiga - cazar una especie no protegida en un coto sin la autorización del titular - es una mera infracción administrativa que por no afectar al bien jurídico protegido en los delitos contra la fauna debería extirparse del Código Penal y ser sancionada únicamente en el ámbito del Derecho administrativo. 